\title{
The Role of Knowledge Brokers in Improving Financial Literacy
}

\author{
Chaouki Mouelhi*1 ${ }^{1}$ and Hajer Hammami²
}

\begin{abstract}
Several governments around the world have tried strategies based primarily on financial education programs to improve the financial literacy of their citizens. In this study, we discuss a new strategy that involves using knowledge transfer activities carried out by intermediary agents, called financial knowledge brokers, to achieve significant improvement in financial literacy. Thus, the aim of this paper is to test the impact of the five activities of financial knowledge brokers (i.e., financial knowledge acquisition, financial knowledge integration, financial knowledge adaptation, financial knowledge dissemination, and creation of links) on financial literacy. For this, we built a database from a questionnaire carried out to nearly 103 financial advisers during the period June 2015 to June 2017. Overall, the results of Structural equation Modeling (SEM) technique showed that the financial knowledge brokerage activities (four of the five activities) have a positive impact on improving financial literacy as well as on its four dimensions, namely financial attitude, financial behavior, basic financial knowledge, and advanced financial knowledge.
\end{abstract}

JEL classification numbers: D80, F65, G20, I20.

Keywords: Financial literacy, Knowledge brokers, Structural equation modeling.

${ }^{1}$ Department of Management Sciences, University of Quebec at Rimouski.

*Corresponding author

2 Department of Management Sciences, University of Quebec at Rimouski

Article Info: Received: March 27, 2021. Revised: April 17, 2021.

Published online: April 19, 2021. 


\section{Introduction}

In present globalization context, where economies and financial systems have become interdependent, low levels of financial literacy turn out to be a global problem. Indeed, in such context of increasing speed of information and communication technologies, the competitiveness has become a crucial element for all countries of the world. Now, success of organizations resides in their ability to develop, use, and transfer knowledge to gain an advantage competitive (Nonaka and Takeuchi (1995), Szulansky). Amongst the competitive advantages, which are essential to the development of a country, we have the financial literacy concept. Over the last two decades, many governments around the world have recognized the seriousness of the economic impact of the low level of financial literacy and bad financial decisions made by their citizens, on a both national and global scale. In addition, several international organizations and researchers have been interested in the concept of financial literacy. For example, the OECD (2006) has identified financial literacy as a process for individuals to "develop the skills and confidence to become more aware of financial risks and opportunities, to make informed choices, to know where to go for help, and to take other effective actions to improve their financial well-being" (OECD (2006)).

In this perspective, Anderloni and Vandone (2010) define financial literacy as a preventive measure that enables individuals to acquire sufficient knowledge to understand financial problems and manage their personal finances in a satisfactory manner, while avoiding indebtedness.

Several studies have mentioned that there is a relationship between financial literacy and financial risk or more specifically financial problems. For example, the study carried out by European Commission and published in 2007, have described the financial risks inherent in low levels of financial literacy of citizens (Habschick et al. (2007)). Furthermore, several studies have shown that the financial crisis of 2008 was due, at least partially, by a harmful combination of bad information, lack of financial experience and cheap credit readily available to US consumers. The effects of this crisis crossed American borders and were probably associated with low levels of financial literacy in most countries (Zia and Xu (2012)). In summary, we can consider financial literacy as a double effect concept:

(i) Negative effect and therefore a threat in the case of low level of financial literacy.

(ii) Positive effect and therefore an opportunity in the case of a high level of financial literacy.

Given the double effects of financial literacy, governments have recognized the need for developing coherent national strategies that provide leadership and action plan to improve financial literacy levels in their countries.

In the literature, there are several research studies that have tried to help these governments to develop reliable and effective national strategies to improve the level of financial literacy of their citizens. However, most of these studies focused on the determinants, the measurement, and the impact of financial literacy. To our 
knowledge, no study has directly addressed the following questions: What are the best ways to improve the level of financial literacy of citizens? who are the main actors best placed to carry out such a mission?

In this study, we propose to consider the knowledge transfer as an indispensable tool for the achievement of the desired result, namely the improving the financial literacy of the population. More specifically, we propose to consider the financial knowledge brokers (i.e., financial advisers, financial planners, asset managers) as being the best actors who can achieve an efficient and sustainable transfer of financial knowledge to citizens. For this, we analyze the relationships between the five activities of the financial knowledge transfer process and financial literacy by a multivariate statistical analysis which is the structural equation modeling (SEM) technique.

This paper proceeds as follows. In the next section, we provide an overview of the financial literacy concept and its dimensions. In section 3, we present the financial knowledge brokers activities. Section 4 presents the research hypotheses. Section 5 describes our research methodology. In section 6, we report and analyse our empirical findings. Finally, section 7 provides a conclusion.

\section{Financial Literacy: Concept and Dimensions}

\subsection{Concept of financial literacy}

Defining the concept of financial literacy is a difficult task because there is no common definition on which academic researchers, financial experts, organizations, practitioners and even politicians have agreed. The ambiguity stems from the fact that the terms: financial literacy, financial knowledge and financial education are often used interchangeably. Certainly, this confusion did not help a clear conceptualization of a such theme. Thus, many researchers have called for standardizing the definition of financial literacy. For example, Schuchardt et al. (2009) have argued that a standardized definition is essential to properly determine the dimensions of financial literacy and thus to measure it correctly.

To achieve this standardized definition, we have conducted a literature review on the major research studies that have attempted to define and conceptualize financial literacy. Hilgert, et al. (2003) have defined financial literacy as financial knowledge which is statistically linked to financial practices. Precisely, they have found that people with more financial literacy are more likely to follow a wide range of recommended financial practices. Several other definitions have emphasized that financial knowledge is the fundamental basis of financial literacy. For example, FINRA (2003) have defined financial literacy: "The understanding that ordinary investors have about market principles, instruments, organizations and regulations". In addition, NCEE (2005) has defined financial literacy as "familiarity with basic economic principles, knowledge of the U.S. economy, and understanding of some key economic terms". Likewise, Lusardi and Mitchell (2007) have viewed financial literacy as familiarity with "the most basic economic concepts that are needed to make sound saving and investing decisions". However, according to Parker et al. 
(2008), financial literacy should be distinguished from general knowledge. Indeed, the authors have found that specific financial knowledge surpasses general knowledge when making a hypothetical investment decision.

Many other studies have linked financial literacy to the ability to manage personal finances. For example, Vitt et al. (2000) have considered financial literacy as "the ability to read, analyze, manage and communicate about the personal financial situation that affects material well-being". Mandell (2007) has defined financial literacy as: "The ability to assess new and complex financial instruments and make informed judgments about the choice of instruments and the spread of their use would be in their long-term best interest". Similarly, several other authors have confirmed the relationship between financial literacy and the ability to manage personal finances (Balatti (2007), Collins (2007), Carswell (2009), Scott (2010), Remund (2010), Huston (2010), etc.). Also, there are many definitions of financial literacy that have focused on the individual skills, its judgments, and its decisions. In other words, these definitions are based on the decision-making skills. For example, Kozup and Hogarth (2008) have defined the financial literacy of an individual as "'a set of critical thinking skills to examine and assess the advantages and disadvantages of a particular decision in relation to its own needs, values and objectives". It is in this context that several other authors have described financial literacy by the different perspectives of financial decision-making. For example, Danes and Haberman (2007) have defined financial literacy as "the ability to interpret, communicate, calculate, develop independent judgment and take actions resulting from these processes in order to thrive in our complex financial world". Moreover, we mention the studies of Rhine and Toussaint-Comeau (2002), Worthington (2004), Stone et al. (2008), and Lusardi and Tufano (2009).

Finally, there are in the literature some definitions that have linked financial literacy to the confidence concept in financial planning. This confidence translates into a capacity for prediction beyond current knowledge. In other words, the ability to manage personal finances, and decision-making skills are necessary and essential achievements for improving financial literacy. However, these achievements are also insufficient, if the individual does not have confidence in his prediction ability of good financial planning. Obviously, the individual who has a good prediction capacity beyond his current knowledge allows him to avoid unpleasant surprises. According to Lusardi and Mitchell (2007), the importance of confidence can come from the fact that individuals generally do not know the extent of their current financial knowledge. Therefore, they should decide what to do (i.e., collect more information or make an informed estimation) based on what they think they know. In addition, Parker et al. (2008) have found that regardless of the effect of current knowledge, it is knowledge confidence that predicts retirement planning and savings, as well as performance when making a hypothetical investment decision. Similarly, several other studies have confirmed the importance of the confidence in defining financial literacy. We refer to Parker and Fischhoff, (2005), Koenig (2007), Bruine et al. (2007), Remund (2010).

In conclusion, the present review of the literature on the main definitions of 
financial literacy allowed us to consider the definition of OECD (2006) as being the most comprehensive. Indeed, the OECD (2006) have defined financial literacy as "the process by which consumers and/or financial investors improve their understanding of financial products and concepts and, through information, education and/or objective advice, develop the skills and confidence to become more aware of financial risks and opportunities, to make informed choices, to know where to turn for help and to take other effective measures to improve their financial well-being".

\subsection{Dimensions of financial literacy}

It is very important to correctly define the dimensions of financial literacy to analyze the impact of financial knowledge transfer activities on improving the level of financial literacy. Unfortunately, there is not valid operational instrument for entirely measuring of financial literacy. Given the nonexistent of a set of standardized dimensions, several prior studies (Shim and al., (2009), Remund (2010), Knoll and Houts (2012), Atkinson and Messy (2012), etc.) have measured the financial literacy by numerous different dimensions. In this study, as suggested by the OECD (2013), financial literacy is defined by the following three dimensions: financial attitude, financial behavior, and financial knowledge.

\subsubsection{Financial attitude}

Shockey (2002) has defined financial attitude as a combination of concepts, information, and emotions about the process of learning and results in a predisposition to act favorably. According to Ajzen (1991), financial attitude is established through economic and non-economic beliefs held by a decision maker on the outcome of a certain behavior, and it is, therefore, considered as a key factor in the personal decision-making process.

\subsubsection{Financial behavior}

Financial behavior is absolutely the most important dimension of financial literacy (OECD (2013)). According to Atkinson and Messy (2012), the positive results of being financially literate are driven by behavior such as planning expenses and building financial security, on the other hand, several behaviors, such as excessive use of credit, may reduce financial well-being (Atkinson and Messy (2012)).

\subsubsection{Financial knowledge}

The financial knowledge has been proposed by Delavande et al. (2008) as a particular kind of human capital that is acquired during the life cycle by learning aspects that affect the ability to manage income, expenditures, and savings in an effective way. According to Danes and Haberman (2007), financial knowledge has been developed through interactions when transmitting and receiving information in groups. In this study, we consider two types of financial knowledge, namely, basic financial knowledge and advanced financial knowledge. 


\section{Financial Knowledge Brokers: Definition and Transfer Activities Process}

\subsection{Definition}

The knowledge transfer is an increasing concept that has developed continuously and rapidly over the past few decades. This concept is at the center of the interests of both academic researchers and policy makers. In several different areas, many studies have shown that there is still a significant gap between the knowledge produced and that which is used in practice. This is exactly the case in the financial world where this gap manifests itself in the low level of financial literacy of the citizens as end users of financial knowledge. In such context, the financial knowledge brokers can play a crucial role in bridging the gap between research and practice and therefore in improving financial literacy. The role of the financial knowledge brokers is not limited to transferring and sharing financial knowledge, but also to provide basic and even more advanced financial education to end users. In this study, we consider financial advisers as financial knowledge brokers who can positively impact the level of financial literacy of their clients.

The definition of knowledge transfer has been considered in different ways in different fields, depending on the type of specialists involved and the goals they pursue. For example, in the field of university research, knowledge transfer refers to "the activities that university researchers undertake to disseminate their knowledge to practitioners working in organizations located outside the university environment" (Amara et al. (2004)). In the health field, Guzman et al. (2008) have considered knowledge transfer as "a process leading to appropriate use of the latest and best research knowledge to help solve concrete problems, information cannot be considered knowledge until it is applied".

The knowledge transfer in management field has been defined by Argote et al. (2000) as: "the process through which one unit (e.g., group, department or division) is affected by the experience of another. [...] Knowledge transfer in organizations manifests itself through changes in the knowledge or performance in the recipient unit". Roy et al. (1995) considered knowledge transfer as "a mechanism for the dissemination, appropriation and use of new knowledge that can lead to the adoption of new individual and organizational behaviors".

In the case of financial literacy, we define financial knowledge transfer in this study as follow: "a process by which knowledge from the financial world is received and used by end users (i.e., citizens) through the deployment of various activities carried out by financial knowledge brokers ". 


\subsection{Transfer activities process}

We propose to identify the activities carried out by financial knowledge brokers through a financial knowledge transfer process which includes five main activities, namely: Financial knowledge acquisition, Financial knowledge integration, Financial knowledge adaptation, Financial knowledge dissemination and Creation of links (see Figure 1).

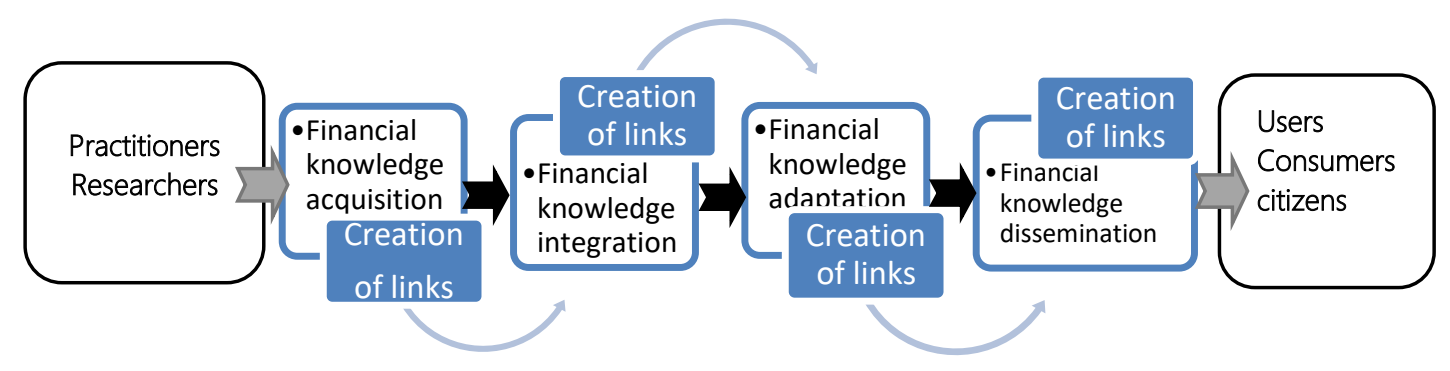

Figure 1: Financial knowledge brokerage process

\subsubsection{Financial knowledge acquisition}

Given that the financial knowledge brokers play the role of an interface agent between the two communities: academics (i.e., researchers, practitioners) and end users (i.e., citizens), they should initially acquire basic knowledge in the financial area to assist users to make good financial decisions. Depending on the individual perspective, the acquisition of new knowledge requires that brokers have already some abilities and skills to recognize the value of financial knowledge transferred to them (Hargadon and Sutton (1997), CHSRF (2003)). In other words, financial knowledge brokers acquire knowledge from researchers and practitioners, and they should recognize what is potentially useful and relevant to transfer it to users. The financial knowledge brokers are key actors to inform users, identify their needs, awaken their interest and finally to propose for them solutions. We consider that financial knowledge brokers will be able to help users acquire the skills and knowledge which they need to take control of their finances and so to ensure their financial well-being.

\subsubsection{Financial knowledge integration}

As initial recipient of financial knowledge generated by researchers and practitioners, the financial knowledge broker should be able to integrate the financial knowledge acquired by its know-how et its expertise to realize a better transfer to users (Cillo (2005), Verona et al. (2006), and Lomas (2007)). According to Hargadon (2003), the knowledge broker is considered a true integrator of 
knowledge, as he collects, combines, and tests the most promising ideas. In addition, the aim of the integration activity is to propose methods and tools to facilitate the financial knowledge transfer from researchers and practitioners to end users. We believe that an effective financial education program will ensure that end users have the tools and knowledge which they need to appeal the services of financial advisors and discuss important financial matters with them. The financial advisors as financial knowledge brokers should be able to integrate certain concepts to facilitate transfer and sharing of financial knowledge.

\subsubsection{Financial knowledge adaptation}

The Knowledge is a product that should be translate into an accessible and clear language in real-life situations. According to Cillo (2005), the adaptation activity achieved by knowledge brokers may reduce the cognitive distance that usually exists between the communities that using different languages and concepts. The financial knowledge brokers should develop a capacity to understand, analyse and exploit financial information that can help end users to make informed decisions in their daily lives and to plan for their future. To do this, financial knowledge brokers should spend the necessary time with end users to ensure that they understand how to read documentation on financial products that fit into their plans (e.g., insurance contracts, account statements, various notices. etc.). In addition, they should review with them the forms to sign and help them to seize the important points. By using an accessible and clear language, the financial knowledge brokers can explain the procedure, advantages and disadvantages of various financial products that cater well to their clients. Therefore, the adaptation activity enables clients to understand the specifications of a new financial product, develop future investment plans, evaluate the risk correctly and so to make an adequate financial decision.

\subsubsection{Financial knowledge dissemination}

Dissemination is an important activity in the financial knowledge transfer process that has been defined as the distribution of information tailored to specific audiences by using specific and effective communication channels (Lavis et al. (2003)). For example, personalized emails, newsletter, website, or Facebook or LinkedIn Professional pages. etc. There are also the workshops and seminars which will give people real opportunities to demystify the financial choices that they face in everyday life. The dissemination activity is an interactive exchange between different communities to ensure the effective use of the knowledge produced (Kerner (2006)). The role of financial knowledge brokers is based, first, on determining the appropriate audience and second, on adapting the message and its inherent means of communication (Huberman and Gather Thuler (1991), Kirst (2000)). 
Also, the dissemination activity allows to offer simple and practical resources designed to meet the needs of basic financial knowledge, namely, concepts easy-tounderstand, accurate practical examples, concrete objectives, scenarios, and potential results focusing on the financial needs of end users at all stages of their lives.

\subsubsection{Creation of links}

The Creation of links between actors with common interests is a key activity of financial knowledge brokers. According to several authors this activity mainly aims to foster greater interaction between knowledge producers and end users through various communication mechanisms that can strengthen effective and sustainable knowledge sharing. Dobbins et al. (2009) have considered the creation of links activity as an integral and effective component of knowledge transfer. In addition, Feldman et al. (2001) have considered the knowledge brokers as bridging actors of groups or individuals, who did not have direct relationship, to facilitate the exchange and transfer of knowledge. According to Hammami et al. (2013), there are two models that can be associated with the emergence of the role of knowledge brokers as actors promoting the creation of links between knowledge producers and end users:

(i) The "social interaction" model (Huberman and Gather Thuler (1991)).

(ii) The "transverse links" model (Scott and Hofmeyer (2007)).

The "social interaction" model has emphasized the creation of formal linkage mechanisms between potential users and the source of knowledge production to facilitate the alignment of individual objectives and so to increase the efficiency of the knowledge transfer process (Huberman and Gather Thuler (1991)). The "transverse links" model has highlighted the ability of knowledge brokers to act as intermediaries and thus disseminate information among often isolated networks (Scott and Hofmeyer (2007)). Finally, given the great importance of the creation of links activity, we propose to view it as a transversal and continuous activity that occurs throughout the financial knowledge transfer process.

\section{Research Hypothesis}

Financial well-being is an important part of our economic and social well-being. The financial knowledge transfer is essential process to reduce the gap between the financial knowledge produced and what is observed in practice. Financial knowledge brokers (e.g., financial advisers, financial planners, asset managers) appear to be the main players in achieving effective and sustainable financial knowledge transfer. Currently, the financial industry is increasingly inundated with information and so the financial decisions have become more difficult and complex. In such context, we consider that financial knowledge brokers can play an important role in improving the financial literacy of their clients as end users of financial knowledge. Specifically, they can provide citizens with basic or even more advanced financial education according to their specific needs. 
H1. The financial knowledge transfer has a positive impact on improving financial literacy.

By looking closely at the different activities of financial knowledge brokerage, we can consider that the knowledge brokers are really "knowledge managers". Furthermore, an effective financial knowledge management requires the acquisition of new financial knowledge. Given the increase complexity of the current financial industry, it is obvious that citizens, who have a low level of financial knowledge, are more likely to make bad financial decisions. For logistical reasons, it is difficult for citizens to directly acquire new financial knowledge. However, we assume that this knowledge acquisition can take place indirectly through the activities of financial knowledge brokerage. Thereby, we consider that the financial knowledge brokers, by playing the role of an interface agent between researchers and end users, should initially acquire new financial knowledge to transfer it to citizens. This is especially true since the financial knowledge brokers have easier access to several channels for acquiring new financial knowledge (e.g., books, manuals, codes of practice and bulletins, electronic databases, etc.). Thus, the knowledge brokers should continually acquire new financial knowledge to effectively participate in improving financial literacy.

H2. The financial knowledge acquisition activity has a positive impact on improving financial literacy.

Integration occurs when financial knowledge brokers reflect on new knowledge acquired to organize it against their previous knowledge. Subsequently, they can enrich, correct, or modify this new knowledge to use it in their future actions. It should be noted that the integration is synonymous with appropriation, which in turn refers to the process by which a person assimilates new knowledge or a new way of conceiving a problem and integrates it into his know-how and expertise. For this reason, we see the integration of knowledge as an essential activity to successful an effective financial knowledge transfer and consequently to improve the financial literacy of citizens.

H3. The financial knowledge integration activity has a positive impact on improving financial literacy.

Once the new knowledge is acquired and integrated by the financial knowledge brokers, it is very important to know how to popularize it and present it in simple and understandable language to the end users. In fact, the financial knowledge adaptation is an essential activity on the path to improving the financial literacy of citizens. This is especially true since the lack of understanding of purely technical and often sophisticated financial language can hamper the ability of individuals to make well-informed financial decisions. The knowledge adaptation activity requires that financial knowledge brokers had specific skills of pedagogues (i.e., good capacity for popularization and synthesis) to facilitate the use of new 
knowledge and demonstrate its value to their clients.

H4. The financial knowledge adaptation activity has a positive impact on improving financial literacy.

The dissemination activity aims to make new financial knowledge more useful and above all more usable for end users. In such activity, the financial knowledge brokers should set up a strategic plan for sharing the knowledge acquired by performing several tasks. First, they detect and synthesize the most relevant knowledge for financial decision-making. Second, they develop key messages. Third, they identify their targets (i.e., citizens with different levels of financial literacy). Finally, they determine windows of opportunity for sharing the knowledge acquired (e.g., personalized emails, newsletter, website, or pages Facebook or LinkedIn Professional, etc.) Therefore, we consider that dissemination activity plays a key role in improving the financial literacy of citizens.

H5. The financial knowledge dissemination activity has a positive impact on improving financial literacy.

The key activity of the financial knowledge brokers is obviously the creation of links. For this reason, we have considered it as a transversal activity and integral component which occurs throughout the knowledge transfer process. The main aim of this activity is to build relationships between knowledge producers and end users to increase the effectiveness of the knowledge transfer process from the financial knowledge producers to the end users. In addition, we note that knowledge transfer is particularly useful and productive when financial knowledge brokers already have some credibility with their various networks. Thus, we consider that the activity of creation of links plays an important role in improving the financial literacy of citizens.

H6. The creation of links activity has a positive impact on improving financial literacy.

\section{Research Methodology}

\subsection{Study data}

\subsubsection{Study population}

The study population concerns financial advisors (investment, insurance, personal tax, and financial services) that working in chartered bank, credit union, trust company, insurance company, and private financial consulting. In practice, it is known that financial advisors help clients to take control of the plaining of their financial security planning and to understand the financial products and services that interest them. As we have already mentioned above, the financial advisors should have the required financial knowledge to help clients to realize their financial goals. In addition, the financial advisors should be good communicators to explain the financial choices of their clients without using a complicated financial jargon. 
In other words, the activities of financial advisors play an important role in the financial knowledge transfer, and in the improvement of the financial literacy level of their clients. For these reasons, we consider financial advisors as financial knowledge brokers in our study. At the beginning, we have selected randomly 150 Canadian financial advisors who are involved in activities of personal financial security. Unfortunately, 29 financial advisors refused to answer our questionnaire. Thereafter, we excluded 18 financial advisors who have not responded to the questionnaire in its entirety. After all, the final population of the study was made up of 103 financial advisors.

\subsubsection{Development of the survey}

In this paper, we have used secondary data collected through a questionnaire survey of a sample of 109 Canadian financial advisors. We have developed the questionnaire based on a systematic review that covers the main theoretical and empirical studies that cover the following topics: financial literacy, knowledge brokerage, and knowledge transfer. The questionnaire is divided into three parts: the first part concerns the knowledge brokers activities, namely, financial knowledge acquisition, financial knowledge integration, financial knowledge adaptation, financial knowledge dissemination, and creation of links.

The second part treats the four dimensions of financial literacy, namely, financial attitude, financial behaviour, basic financial knowledge, and advanced financial knowledge. The third part focuses on the socio-professional profile of financial knowledge brokers (gender, education level, status, experience, etc.). To the best of our knowledge, this questionnaire is the first empirical study in Canada on the impact of financial knowledge brokers activities on improving financial literacy.

\subsubsection{Collection of data}

All 150 financial advisors selected randomly were contacted for an interview. The survey was administered by face-to-face or telephone between the 16th of June 2015 and the 15 th of June 2016. Out of the 150 financial advisors, there are 29 refused to participate in the survey, and 18 respondents were excluded because they did not respond to all the questions. Finally, the survey generated 103 valid questionnaires which gave us a net response rate of $68.67 \%$ (103/150).

\subsection{Coding of data}

\subsubsection{Dependent variable: Financial literacy}

The measure of financial literacy includes 31 items that were divided into four dimensions: "financial attitude" (9 items), "financial behaviour" (15 items), "basic financial knowledge" (3 items) and "advanced financial knowledge" (4 items). For each statement, a 5-point scale ranging from $1(0 \%-20 \%$ : very weak) to $5(80 \%$ - $100 \%$ : very strong) was used. The sum of the response scores for the four dimensions, which initially ranged from 5 to 20 , was weighted to consider "not relevant" answers. Thus, for each respondent, the sum of the score was divided by 
the number of applicable items. Even though the initial index has integer values from 1 to 5, once weighted, it can take on non-integer values. Given that the four indices were based on multiple-item scales, we have carried out a Principal Components Factor Analysis (PCFA) with Varimax Rotation on the construct scales to examine their unidimensionality (Ahire and Devaray (2001), and Hammami et al. (2013)).

Table 1 presents results of the PCFA and the internal reliability coefficient for the four dimensions of the dependant variable (i.e., the financial literacy) with a multiple-item scale.

Table 1: The PCFA and the Internal Reliability Coefficient for the four Financial Literacy Dimensions

\begin{tabular}{|l|c|c|c|}
\hline \multicolumn{1}{|c|}{ Dimension } & $\begin{array}{c}\text { Explained } \\
\text { Variance }\end{array}$ & Eigenvalue & $\begin{array}{c}\text { Cronbach's } \\
\text { Alpha }\end{array}$ \\
\hline Financial attitude & $67.83 \%$ & 2.39 & 0.87 \\
\hline Financial behaviour & $63.14 \%$ & 1.87 & 0.78 \\
\hline Basic financial knowledge & $58.92 \%$ & 1.65 & 0.73 \\
\hline Advanced financial knowledge & $61.36 \%$ & 1.59 & 0.82 \\
\hline
\end{tabular}

Results of Table 1 indicate that a multiple-item scale satisfies the unidimensionality criterion. Indeed, the explained variance of each dimension is greater than $50 \%$ and the eigenvalues range from 1.59 to 2.39 , which means that they are all greater than 1. Additionally, Cronbach's Alpha score is equal to 0.87 for financial attitude and 0.82 for advanced financial literacy which indicates that the items composing their indices present a good internal consistency. The Cronbach's alpha scores of financial behavior (0.78) and basic financial literacy (0.73) are greater than 0.70 but less than 0.80 which shows that the items composing their indices present an acceptable internal consistency.

\subsubsection{Independent variables: financial knowledge transfer activities}

The independent variables were the five financial knowledge transfer activities, namely, financial knowledge acquisition, financial knowledge integration, financial knowledge adaptation, financial knowledge dissemination, and creation of links. These activities were operationalized using five indices. Moreover, we have measured these indices by 41 items divided as follows: "acquisition, activity" (9 items), "integration activity" (5 items), "adaptation activity" (15 items), "dissemination activity" (8 items) and "creation of links activity" (4 items). For each item, a 5-point scale ranging from 1 (never) to 5 (very often) is used. The sum of the response scores for the five indices, which initially ranged from 5 to 25 , was weighted to consider "not relevant" answers. Thereby, we have divided the sum of 
the score of each respondent by the number of applicable items. Hence, although the initial index has integer values from 1 to 5, after weighing them, it can take on non-integer values. As in the case of the dependent variable, we have conducted a Principal Components Factor Analysis (PCFA) with Varimax Rotation on the construct scales (Ahire and Devaray (2001), and Hammami et al. (2013)). Results of this PCFA are shown in Table 2.

Table 2: The PCFA and the Internal Reliability Coefficient for the five Financial Knowledge Transfer Activities

\begin{tabular}{|l|c|c|c|}
\hline \multicolumn{1}{|c|}{ Activities } & $\begin{array}{c}\text { Explained } \\
\text { Variance }\end{array}$ & Eigenvalue & $\begin{array}{c}\text { Cronbach's } \\
\text { Alpha }\end{array}$ \\
\hline Financial knowledge acquisition & $63.28 \%$ & 2.18 & 0.79 \\
\hline Financial knowledge integration & $59.76 \%$ & 1.81 & 0.68 \\
\hline Financial knowledge adaptation & $55.38 \%$ & 1,52 & 0.71 \\
\hline Financial knowledge dissemination & $62.43 \%$ & 1.78 & 0.74 \\
\hline Creation of links & $65.72 \%$ & 1.96 & 0.76 \\
\hline
\end{tabular}

Results of Table 2 indicate that the multiple-item scale satisfies the unidimensionality criterion. First, the explained variance of each financial knowledge transfer activity is greater than $50 \%$. Second, the eigenvalues are all greater than 1. Indeed, we notice that the smallest eigenvalue is that of the adaptation activity with 1.52 , while the higher is that of the acquisition activity, namely, 2.18. Finally, the findings of Table 2 show that the Cronbach's Alpha scores of four activities are greater then 0,70 but less than 0.80 , namely, financial knowledge acquisition (0.79), financial knowledge adaptation (0.71), financial knowledge dissemination (0.74) and creation of links (0.76). Such results indicate that the items composing indices of these four activities present an acceptable internal consistency. However, we notice that he Cronbach's Alpha score of the financial knowledge integration is equal to 0.68 which indicates that the items composing index of this activity present a questionable internal consistency.

\subsection{Data analysis}

The data analysis aims to validate the measures of the variables and then establish the causal relationships to test our research hypotheses. For this, we have used structural equation modeling technique (SEM) via the EQS program, namely, EQS 6.1 to investigate the confirmatory measurement models (i.e., confirmatory factor analysis) and then to examine the confirmatory structural models (i.e., the structural equations). It should be noted that the structural equation modeling technique (SEM) allow to simultaneously evaluate the fit of the different hypothetical models as well as their consistency with the data (Byrne (2006)). In this study, under the assumption that the data are normally distributed, we have used the maximum likelihood method. In addition, we recall that the EQS 6.1 operates on a normalized variance-covariance matrix derived from the raw database (Bentler (2006)). 
In the confirmatory factor analysis, which aims to examine the fit of the different hypothetical models, six fit indices were used, namely, the normed chi-square $\left(\chi^{2} / d f\right)$, the Root Mean Square Error of Approximation (RMSEA), the Goodnessof- Fit Index (GFI), the Adjusted Goodness-of-Fit index (AGFI), the Comparative Fit Index (CFI) and the Non-Normed Fit Index (NNFI) (Hair et al. (1998), Kline (1998), Byrne (2006), and Bentler (2006)).

These six fit indices should respect some specific values to conclude that the hypothetical model is acceptable. Indeed, the normed chi-square $\left(\chi^{2} / d f\right)$ should be less than or equal to 3, the RMSEA should be less than 0.10, GFI and AGFI should be greater than 0.80 and CFI and NNFI should have values which surpass 0.90 (Segars and Grover (1993)). Moreover, we have examined the convergent validity of each hypothetical model through the composite reliability $(\rho)$ and the variance extracted $(V E)$. The recommended value of the composite reliability $(\rho)$ should be greater than 0.70 and that of the variance extracted $(V E)$ should be greater than 0.50 (Kline (1998)).

Finally, in the case where the six fit indices indicate a minimal difference between the hypothetical models, we recommend the use of the AIC fit index to determine which model fits the data best (Hair et al. (1998), and Kline (1998)).

\section{Empirical Results}

\subsection{Results of the confirmatory factor analysis}

We have carried out a confirmatory factor analysis to evaluate the dimensional scales of our two constructs, namely, the financial literacy and the financial knowledge transfer. Thus, we have run two structural measurement constructs. The first construct consists in testing the capacity of a main latent variable (i.e., the financial literacy) to represent the other latent variables which are the four dimensions (i.e., financial attitude, financial behavior, basic financial knowledge, and advanced financial knowledge). The second construct consists in testing a generic latent variable (i.e., the financial knowledge transfer) which is a representation of a set of latent variables, namely, the five activities (i.e., financial knowledge acquisition, financial knowledge integration, financial knowledge adaptation, financial knowledge dissemination, and creation of links). In this confirmatory factor analysis, we have modelized two second-order factors to track down the substantial common variance on the financial literacy path (first construct) and on the financial knowledge transfer path (second construct). Table 3 presents the results of the fit indices and the convergent validity of the two constructs. The results presented in Table 3 show that the first construct adequately describes the data. Indeed, the normed chi-square $\left(\chi^{2} / d f\right)$, is equal to 2.33 and therefore it is less than 3 , which means that the observed data fit very well to the proposed model. In addition, the other five fit indices also meet the basic requirements and so they confirm an appreciable fit of the first construct. 
Table 3: Confirmatory Factor Analysis Results

\begin{tabular}{|c|c|c|c|c|c|c|c|c|}
\hline \multirow{2}{*}{ Constructs } & \multicolumn{4}{|c|}{ Absolute fit measures } & \multicolumn{2}{c|}{$\begin{array}{c}\text { Incremental } \\
\text { fit measures }\end{array}$} & \multicolumn{2}{c|}{$\begin{array}{c}\text { Convergent } \\
\text { validity }\end{array}$} \\
\cline { 2 - 8 } & $\chi^{2} /$ df & RMSEA & GFI & AGFI & CFI & NNFI & $\rho$ & VE \\
\hline $\begin{array}{c}\text { Financial } \\
\text { literacy }\end{array}$ & 2.33 & 0.093 & 0.856 & 0.827 & 0.955 & 0.931 & 0.876 & 0.664 \\
\hline $\begin{array}{c}\text { Financial } \\
\text { knowledge } \\
\text { transfer }\end{array}$ & 2.03 & 0.087 & 0.831 & 0.816 & 0.939 & 0.912 & 0.857 & 0.611 \\
\hline
\end{tabular}

As we can see in Table 3, the RMSEA is equal to 0.093 which is lesser than the recommended value of 0.10 , the GFI and the AGFI are both greater than 0.80 (i.e., $\mathrm{GFI}=0.856$ and $\mathrm{AGFI}=0.827$ ), the $\mathrm{CFI}$ and the NNFI have values which are greater than the required limit of 0.90 (i.e., $\mathrm{CFI}=0.955$ and $\mathrm{NNFI}=0.931$ ). Similarly, the results of Table 3 indicate that second construct adequately describes the data since the six fit indices meet the basic requirements and so they validate the appreciable fit of this construct. In Fact, the normed chi-square $\left(\chi^{2} / d f\right)$, is equal to 2.03 (i.e. less than 3), the RMSEA is equal to 0.087 (i.e. less than 0.10), the GFI and the AGFI are equal to 0.831 and 0.816 , respectively (i.e., more than 0.80 ), the CFI and the NNFI are both greater than 0.90 , namely 0.939 and 0.912 , respectively. Furthermore, results of Table 3 confirm the convergent validity of the two constructs since all composite reliabilities ( $\rho$ (first construct) $=0.876$ and $\rho$ (second construct $)=0.857$ ) and variance extracted measures ( $V E$ (first construct) $=0.664$ and $V E$ (second construct) $=0.611$ ) surpassed the suggested values (i.e., 0.70 and 0,50 , respectively). Finally, we note down that for the two constructs all factor loadings exceed 0.50 with a significant level of 0.05 . Indeed, for the first construct (i.e., financial literacy), the factor loadings ranged from 0.59 to 0.93 , and for the second construct (i.e., financial knowledge transfer) they ranged from 0.55 to 0.96 (See Appendices).

\subsection{Results of the structural equation analysis}

Once the fit of the two measuring constructs has been validated by the confirmatory factor analysis, the next step of the study is to test our six research hypotheses by examining the structural relationships between the variables in the context of two structural models: an additive model (model \#1) and a direct model (model \#2). The model \#1 reflects a significant additive relationship between financial brokers' knowledge transfer, as a generic variable, and financial literacy. The model \#2 reflects a significant direct relationship between the five financial knowledge transfer activities and the financial literacy, as dependent variable. 


\subsubsection{Results of the additive model (model \#1)}

The additive model tests the hypothesis 1 (H1), namely, the direct relationship between financial brokers' knowledge transfer (second order model) and financial literacy (first order model). First, we have examined the fit of the model \#1. Table 4 presents the eight fit indexes' values ( $\chi^{2} / d f$, RMSEA, GFI, AGFI, CFI, NNFI, AIC and $C A I C$ ) which are all satisfactory and and perfectly respect the recommended values. Therefore, these results indicate a good fit of the model \#1.

Table 4: Fit Indexes' Values of the Additive Model (Model \#1)

\begin{tabular}{|l|l|l|l|l|l|l|l|l|}
\hline & $\chi^{\mathbf{2}} / \mathbf{d f}$ & RMSEA & GFI & AGFI & CFI & NNFI & AIC & CAIC \\
\hline Model \#1 & 1.779 & 0.039 & 0.932 & 0.879 & 0.971 & 0.935 & -8.145 & -.24 .937 \\
\hline
\end{tabular}

Recommended values: $\chi^{2} / d f \leq 3$ indicates that the model is appreciable, RMSEA $\leq 0.08, \mathrm{GFI} \geq$ $0.80, \mathrm{AGFI} \geq 0.80 ; \mathrm{CFI} \geq 0.90 ; \mathrm{NNFI} \geq 0.90, \mathrm{AIC}$ and CAIC the smallest value.

Second, after having confirmed the satisfactory fit of the model \#1, hereby we can retain the correlation coefficients as well as the percentages of explained variance $\left(\mathrm{R}^{2}\right)$ of the endogenous variables to verify the validity of hypothesis $1(\mathrm{H} 1)$. The Figure 2 indicates that the path coefficient was statistically significant at $5 \%$ of significance level. Precisely, the relationship between financial knowledge transfer and financial literacy had a high path coefficient value, namely, 074, as well as a high $R^{2}$ value equal to 0.83 .

These results clearly indicate the strong relationship between the two variables.

In other words, it is reasonable to conclude that financial knowledge transfer through its five activities (i.e.,"financial knowledge acquisition", "financial knowledge integration", "financial knowledge adaptation", "financial knowledge dissemination" and "creation of links") has a positive and significant impact on improving financial literacy. Thus, these results allow us to accept H1. 


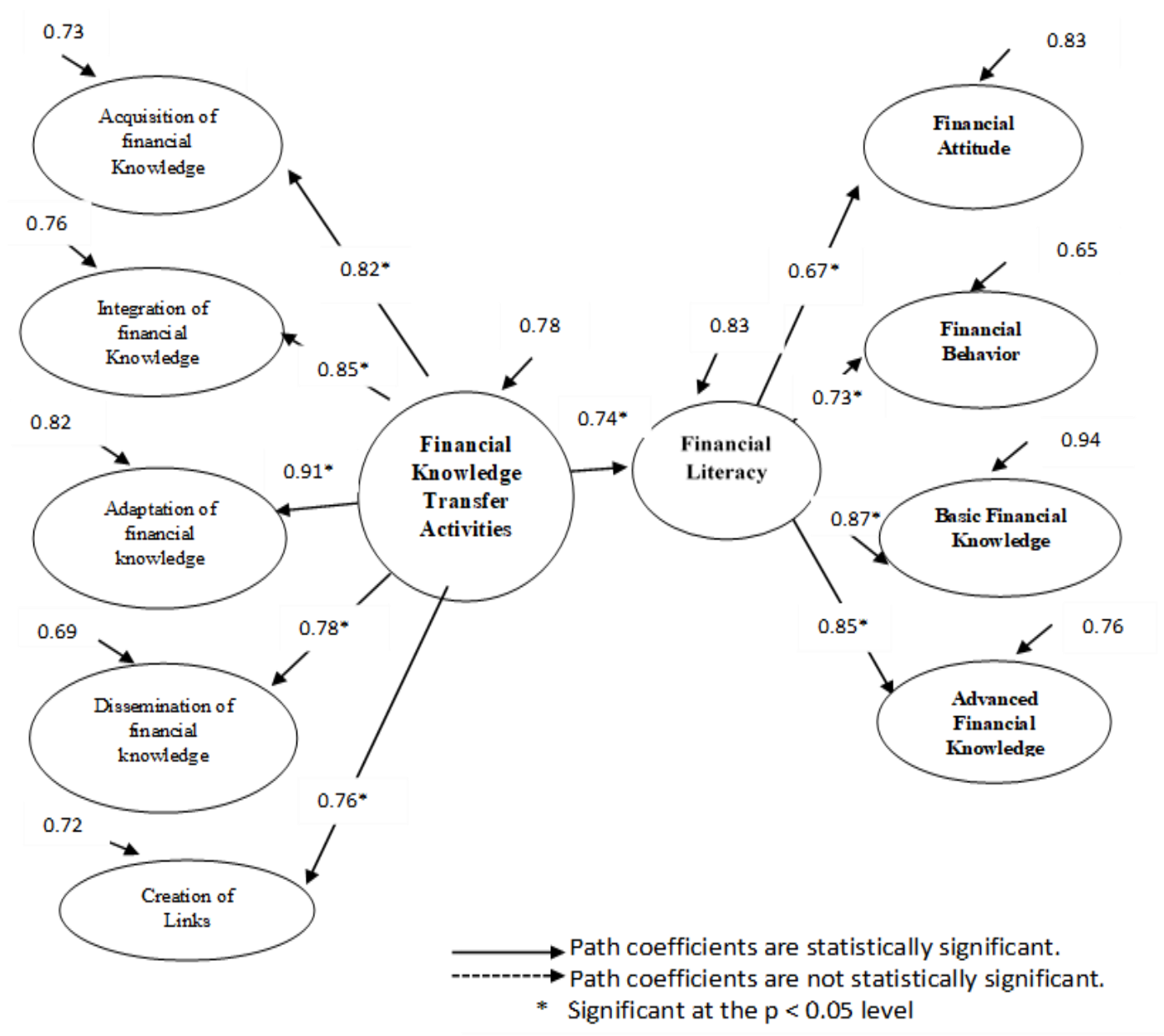

Figure 2. Results of the additive model

\subsubsection{Results of the direct model (model \#2)}

The direct model aims to test the five research hypotheses (H2, H3, H4, H5 and H6) relating to the existence of a positive impact of each activity of knowledge brokers ("financial knowledge acquisition", "financial knowledge integration", "financial knowledge Adaptation", "financial knowledge dissemination" and "creation of links") on improving financial literacy. We have started by examining the adjustment of the direct model according to the results of the Table 5 which presents the eight fit indexes' values ( $\chi^{2} / d f, R M S E A, G F I, A G F I, C F I, N N F I, A I C$ and $C A I C$ ) of the model \#2. Overall, the results Table 5 indicate a good fit of the model 2 since all fit indexes' values are satisfactory and perfectly respect the recommended values. 
Table 5: Fit Indexes' Values of the Direct Model (Model \#2)

\begin{tabular}{|l|l|l|l|l|l|l|l|l|}
\hline & $\chi^{\mathbf{2}} / \mathbf{d f}$ & RMSEA & GFI & AGFI & CFI & NNFI & AIC & CAIC \\
\hline Model \#2 & 1.707 & 0.035 & 0.939 & 0.853 & 0.974 & 0.941 & -6.639 & -.22 .128 \\
\hline
\end{tabular}

Recommended values: $\chi^{2} / d f \leq 3$ indicates that the model is appreciable, RMSEA $\leq 0.08$, GFI $\geq$ $0.80, \mathrm{AGFI} \geq 0.80 ; \mathrm{CFI} \geq 0.90 ; \mathrm{NNFI} \geq 0.90, \mathrm{AIC}$ and CAIC the smallest value.

Subsequently, we have tested the five research hypotheses $(\mathrm{H} 2, \mathrm{H} 3, \mathrm{H} 4, \mathrm{H} 5$ and $\mathrm{H} 6)$ by interpreting the correlation coefficients and the percentages of explained variance $\left(\mathrm{R}^{2}\right)$ which are presented in Figure 3. First, the structural model shows that the activity of financial knowledge acquisition has a significant relationship with financial literacy since the path coefficient value is equal to 0.63 and it is statistically significant at $5 \%$ of significance level. This result allows us to accept the hypothesis $2(\mathrm{H} 2)$.

Next, the path coefficient between the activity of financial knowledge integration and the financial literacy is statistically significant at $5 \%$ of significance level, with a path coefficient value equal to 0.66 . Therefore, the hypothesis 3 (H3) is also accepted. Then, the structural model shows that the relationship between the activity of financial knowledge adaptation and financial literacy is significant at $5 \%$ of significance level and the corresponding path coefficient value is equal to 0.73 . Such result leads us to accept the hypothesis 4 (H4).

Thereafter, as it is mentioned in Figure 3, the path coefficient between the activity of financial knowledge dissemination and financial literacy is not statistically significant even at $10 \%$ of significance level ( $\mathrm{p}$-value $=0.126)$. Thus, the hypothesis 5 (H5) is rejected. In addition, the result of the structural model allows us to accept the hypothesis 6 (H6) since the significant (at $5 \%$ of significance level) relationship between creation of links' activity and financial literacy displays the highest path coefficient value, namely 0.89 .

Finally, we notice that the percentage of explained variance $\left(\mathrm{R}^{2}\right)$ of the dependent variable (i.e., financial literacy) is equal to 0.91 . Overall, this high value of $R^{2}$ supports the results that we have found.

According to these results, the financial knowledge brokerage appears to be a very useful tool in improving the financial literacy of the population. In other words, financial knowledge brokers appear to be the actors who are best placed to carry out such a mission. 


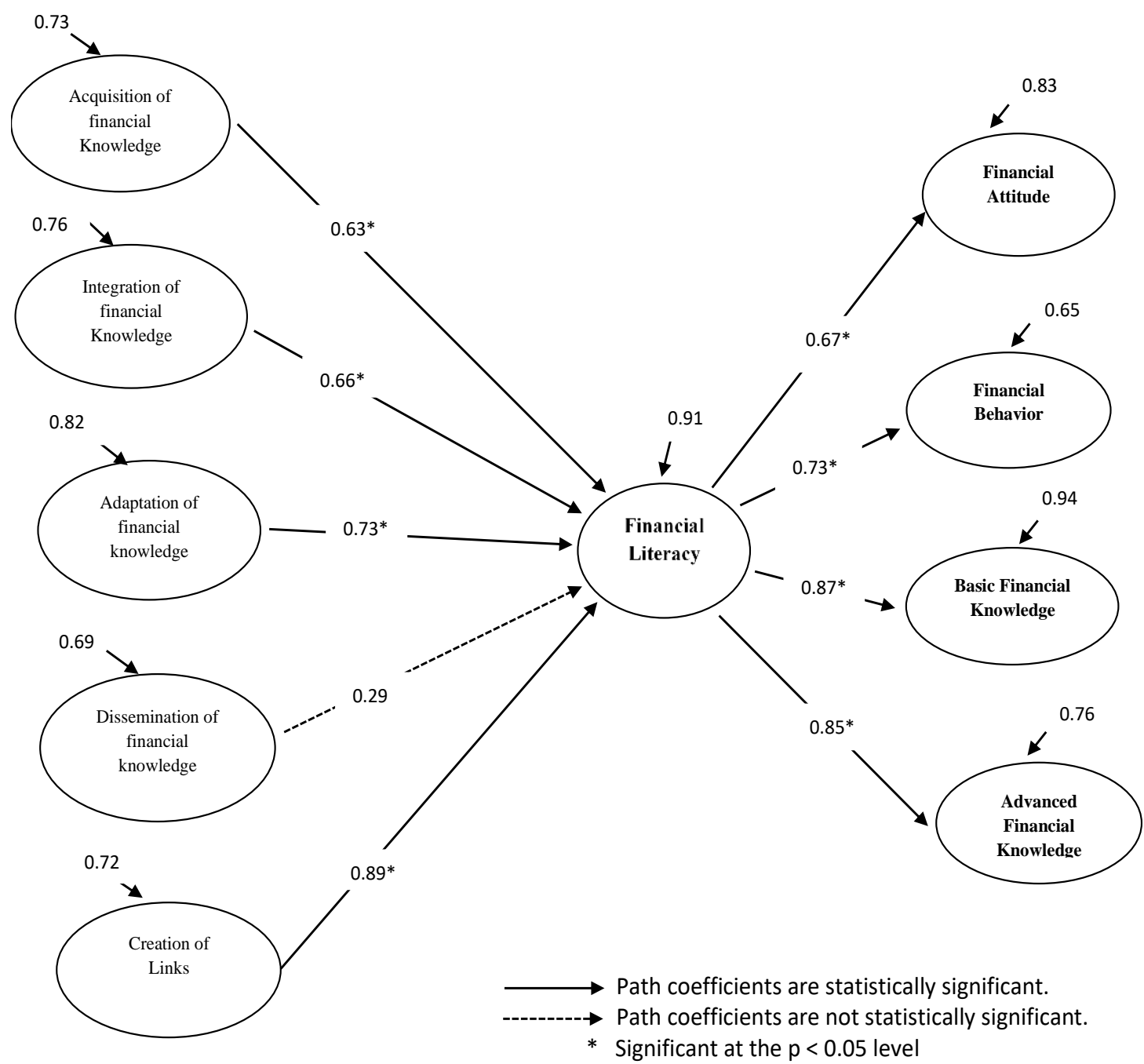

Figure 3. Results of the direct model

\section{Conclusion}

The structural equations modeling (SEM) is a statistical technique which often used to representing, estimating, and testing the structural relationship between measured variables and latent constructs. In this study, we have employed this technique to analyze the structural relationships between the activities of the financial knowledge transfer process and financial literacy. The main findings of the structural equations modeling (SEM) have allowed us to bring out the major conclusions discussed in the following. The results from the additive model showed a direct relationship 
between financial knowledge transfer and financial literacy. This result confirms the role played by financial advisers as financial knowledge brokers in improving financial literacy. To our knowledge, this paper is the first empirical study that has statistically validated the positive impact of financial knowledge transfer carried out by financial advisers on improving the level of financial literacy of citizens.

The results of the direct model showed that four activities of the knowledge transfer process (i.e., financial knowledge acquisition, financial knowledge integration, financial knowledge adaptation, and creation of links) have a positive impact on improving financial literacy. However, we have found that dissemination activity is not directly related to financial literacy. It is entirely legitimate to look for the causes of such a result since financial knowledge dissemination is an essential activity in the financial knowledge transfer process. For this, we advance the possibility that one of the four other activities of the knowledge transfer process (i.e., financial knowledge acquisition, financial knowledge integration, financial knowledge adaptation or creation of links) mediates the relationship between dissemination activity and financial literacy. Therefore, we propose a first extension of this paper which consists in using the sequential procedure initially recommended by Baron and Kenny (1986) and confirmed by several other authors (Roussel and Wacheux (2005) and Mackinon et al. (2007)) to test the mediation' hypotheses of one of the four activities (acquisition, integration, adaptation or creation of links) in the process of the impact of the dissemination activity, as independent variable, on the improving of financial literacy as dependent variable.

The first limitation that we have identified in this study relates to the period during which we carried out all the questionnaires used to build the database. This period is spread over twelve months, namely from June 16, 2015 to June 15, 2016. We believe that to obtain a good intrinsic quality of the database, it is preferable to carry out the questionnaires over a shorter period especially since the dependent variable (financial literacy level of citizens) can experience a significant change over a period of one year. The second limitation that we have noted in this study relates to the small size of the sample. Indeed, although the response rate $(68.67 \%(103 / 150))$ is satisfactory, the number of respondents (103) can probably limit the significance of certain variables. Thus, we suggest a second possible extension of this study which consists in expanding the sample size by including all other professionals in the financial sector and not only financial advisors. In addition, it would be interesting to further enrich the measurement scales of certain variables of the questionnaire (e.g., a 10-point scale ranging from $1(0 \%-10 \%$ : very weak) to 10 (90 \% - $100 \%$ : very strong). By this way we can obtain in future studies more general and robust results regarding to the primordial role of financial knowledge brokers in the financial education of citizens and consequently in improving their financial literature. 


\section{References}

[1] Ahire, S.L. and Devaray, S. (2001). An empirical comparison of statistical construct validation approaches.

EEE Transactions on Engineering Management, vol. 48, no.3, pp. 319 - 329.

[2] Ajzen, I. (1991). The theory of planned behavior. Organizational Behavior and Human Decision Processes, vol. 50, no. 2, pp. 179 - 211.

[3] Amara, N., Ouimet, M., and Landry, R. (2004). New evidence on instrumental, conceptual, and symbolic utilization of university research in government agencies. Science Communication, vol. 26, no. 1, pp. 75 - 107.

[4] Anderloni, L. and Vandone D. (2010). Risk of over-indebtedness and behavioral factors. Department of Economics University of Milan, Working Paper, no. 25, https://www.researchgate.net/publication/46466330_Risk_of_overindebtedness_and_behavioural_factors.

[5] Argote, L., Ingram, P., Levine, J.M, and Moreland, R.L. (2000). Knowledge transfer in organizations: Learning from the experience of others. Organizational Behavior and Human Decision Process, vol. 82, no. 1, pp. 1 8 .

[6] Atkinson, A. and Messy, F.A. (2012). Measuring Financial Literacy: Results of the OECD/International Network on Financial Education (INFE) Pilot Study. OECD Working Papers on Finance, Insurance and Private Pensions, No. 15, OECD Publishing. http://dx.doi.org/10.1787/5k9csfs90fr4-en

[7] Balatti, J. (2007). Financial literacy and social networks-what's the connection? Presentation at the Adult Learning Australia National Conference, Cairns, November 2007.

[8] Baron, R.M. and Kenny, D.A. (1986). The moderator-mediator variable distinction in social psychological research: Conceptual, strategic, and statistical considerations. Journal of Personality and Social Psychology, vol. 51, pp. $1173-1182$.

[9] Bentler, P.M. (2006). EQS 6 Structural Equations Program Manual,” Encino, CA: Multivariate Software, Inc.

[10] Bruine de Bruin, W., Parker, A.M., and Fischhoff, B. (2007). Individual differences in adult decision-making competence. Journal of Personality and Social Psychology, vol. 92, no. 25, pp. 938 - 956.

[11] Byrne, B.M. (2006). Structural equation modeling with EQS and EQS: Basic concepts, applications, and programming. New Jersey: Second Edition Mahwah.

[12] Canadian Health Services Research Foundation (CHSRF). (2003). The theory and practice of knowledge brokering in Canada's health system. Ottawa: Canadian Health Services Research Foundation.

[13] Carswell, A.T. (2009). Does housing counseling change consumer financial behaviors? Evidence from Philadelphia. Journal of Family and Economic Issues, vol. 30, no. 4, pp.339 - 356. 
[14] Cillo, P. (2005). Fostering market knowledge use in innovation: The role of internal brokers. European Management Journal, vol. 23, no. 4, pp. 404 - 412.

[15] Collins, J.M. (2007). Exploring the design of financial counseling for mortgage borrowers in default. Journal of Family and Economic Issues, vol. 28, no. 2, pp. 207-226.

[16] Danes, S. and Haberman H. (2007). Teen financial knowledge, self efficacy, and behavior: a gender view. Journal of Financial Counseling and Planning, vol. 18 , pp. 48 - 60.

[17] Delavande, A., Rohwedder, S., and Willis, R. (2008). Preparation for Retirement, Financial Knowledge and Cognitive Resources. MRRC Working Paper Series 190.

[18] Dobbins, M., Robeson, P., Ciliska, D., Hanna, S., Cameron, R., O'Mara, L., DeCorby, K., and Mercer, S. (2009). A description of a knowledge broker role implemented as part of a randomized controlled trial evaluating three knowledge translation strategies. Implementation Science, vol. 4, no. 23, pp. 1 $-32$.

[19] Feldman, P.H., Nadash, P., and Gursen, M. (2001). Improving communication between researchers and policy makers in long-term care: or researchers are from Mars; policy makers are from Venus. The Gerontologist, vol. 4, no. 3, pp. $312-321$.

[20] Financial Industry Regulatory Authority (FINRA). (2003). NASD investor literacy research: Executive summary. Accessed March 11, 2009. Available at: http://www.finrafoundation.org/surveyexecsum.pdf

[21] Guzman, J.A., Yassi, A., Baril, R., and Loisel, P. (2008). Decreasing occupational injury and disability: the convergence of systems theory, knowledge transfer and action research. WORK: A Journal of Prevention, Assessment \& Rehabilitation, vol. 30, no.3, pp. 229 - 239.

[22] Habschick, M., Seidl, B., and Evers, J. (2007). Survey of Financial Literacy Schemes in the EU27. EVERS and JUNG-Financial Services and Research Consulting, November, pp. 1-108.

[23] Hair, J.F., Anderson, R.E., Tatham, R.L., and Black, W. (1998). Multivariate data analysis. 5th edition, Prentice Hall.

[24] Hammami, H., Amara, N., and Landry, R. (2013). Organizational climate and its influence on brokers' knowledge transfer activities: a structural equation modeling. International Journal of Information Management, vol.13, pp. 105 118.

[25] Hargadon, A. and Sutton, R.I. (1997). Technology brokering and innovation in a product development firm. Administrative Science Quarterly, vol. 42, pp. $716-749$.

[26] Hargadon, A. (2003). How breakthrough happen: technology brokering and the pursuit of innovation. Cambridge. Harvard Business School Press.

[27] Hilgert, M.A., Hogarth, J.M., and Beverly S.G. (2003). Household financial management: The connection between knowledge and behavior. Federal Reserve Bulletin, vol. 89, no. 7, pp. 309 - 322. 
[28] Huberman, M. and Gather Thuler, M. (1991). De la recherche à la pratique: Éléments de base. Berne, PETER LANG.

[29] Huston, S.J. (2010). Measuring financial literacy. Journal of Consumer Affairs, vol. 44, pp. 296 - 316.

[30] Kerner, J.F. (2006). Knowledge translating versus knowledge integration: A Funder's perspective. The Journal of Continuing Education in the Health Professions, vol. 26, pp. 72 - 80.

[31] Kirst, M.W. (2000). Bridging education research and education policy making. Oxford Review of Education, vol. 26, no. 3, pp. 379 - 391.

[32] Kline, R.B. (1998). Principles and practice of structural equation modeling. New York: Guilford Press.

[33] Knoll, M. and Houts, C. (2012). The financial knowledge scale: An application of item response theory to the assessment of financial literacy. Journal of Consumer Affairs, vol. 46, no. 3, pp. 381 - 410.

[34] Koenig, L. (2007). Financial Literacy Curriculum: The Effect on Offender Money Management Skills. Journal of Correctional Education, vol. 58, no. 1, pp. 43 - 56.

[35] Kozup, J. and Hogarth, J. (2008). Financial Literacy, Public Policy, and Consumers' Self-protection-More Questions, Fewer Answers. Journal of Consumer Affairs, vol. 42, Summer, pp. 127 - 136.

[36] Lavis, J.N., Robertson, D., Woodside, M.J., McLeod, B.C., and Abelson, J. (2003). How can research organizations more effectively transfer research knowledge to decision makers? The Milbank Quarterly, vol. 81, no. 2, pp. 221248.

[37] Lomas, J. (2007). The in-between world of knowledge brokering. BMJ, vol. 334, pp.129 - 132.

[38] Lusardi, A. and Mitchell, O. (2007). Financial literacy and retirement preparedness: Evidence and implications for financial education. Business Economics, vol.42, pp. 35 - 44.

[39] Lusardi, A. and Tufano, P. (2009). Debt Literacy, Financial Experience, and Overindebtedness. Harvard Business School, Working Paper.

[40] MacKinnon, D.P., Fairchild, A.J., and Fritz, M.S. (2007). Mediation Analysis. Annual Review of Psychology, vol. 58, pp. 593 - 614.

[41] Mandell, L. (2007). Financial literacy of high school students. In J.J. Xiao (Ed.) Handbook of Consumer Finance Research, NY: Springer, pp. 163 - 183.

[42] National Council for Economic Education (2005). What American teens and adults know about economics. Accessed February 25, 2009. Available at http://www.ncee.net/cel/WhatAmericansKnowAboutEconomics_0426053.pdf

[43] Nonaka, I. and Takeuchi, H. (1995). The knowledge-creating company: How Japanese companies create the dynamics of innovation, New York: Oxford University Press. 
[44] Organization for Economic Co-Operation and Development (OECD). (2006). Improving Financial Literacy: Analysis of Issues and Policies. OECD Journal: Financial Market Trend, vol. 2005, issue 2, pp. 111-123.

[45] Organisation for Economic Co-Operation and Development (OECD). (2012). Financial Literacy Framework, in OECD, PISA 2012 Assessment and Analytical Framework: Mathematics, Reading, Science, Problem Solving and Financial Literacy. 2013, OECD Publishing, doi: 10.1787/9789264190511-7en

[46] Parker, A.M. and Fischhoff, B. (2005). Decision-making competence: External validation through an individual-differences approach. Journal of Behavioral Decision Making, vol. 18, pp. 1 - 27.

[47] Parker, A.M., Yoong, J., Bruine de Bruin, W., and Willis, R. (2008). (Over)confidence and economic behavior. Paper presented at the Conference on Understanding Economic Decision Making. Jackson, WY, September 2008.

[48] Remund, D.L. (2010). Financial literacy explicated: The case for a clearer definition in an increasingly complex economy. Journal of Consumer Affairs, vol. 44, no. 2 , pp. 276 - 295.

[49] Rhine, S. and Toussaint-Comeau, M. (2002). Adult Preferences in the Delivery of Personal Financial Information. Financial Counseling and Planning, vol. 13, no. 2, pp. $11-25$.

[50] Roussel, P. and Wacheux, F. (2005). Management des ressources humaines: méthodes de recherche en sciences humaines et sociales. Bruxelles: De Boeck.

[51] Roy, M., Guindon, J.C., and Fortier, L. (1995). Transfert de connaissances revue de littérature et proposition d'un modèle. Institut de recherche en santé et en sécurité du travail du Québec, pp. 50 - 53.

[52] Schuchardt, J., Hanna, S.D., Hira, T.K., Lyons, A.C., Palmer, L., andXiao, J.J. (2009). Financial literacy and education research priorities. Journal of Financial Counseling and Planning, vol. 20, Issue 1, pp. 84 - 95.

[53] Scott, C. and Hofmeyer, A. (2007). Acknowledging complexity: Critically analyzing context to understand interdisciplinary research. Journal of Interprofessional Care, vol. 21, no. 5, pp. $491-501$.

[54] Scott, R.H. (2010). Credit card ownership among American high school seniors: 1997-2008. Journal of Family and Economic Issues, vol. 31, no. 2, pp.151-160.

[55] Segars, A.H. and Grover, V. (1993). Re-examining perceived ease of use and usefulness: a confirmatory factor analysis. MIS Quarterly, vol. 17, pp. 517 522.

[56] Shim, S., Xiao, J.J., Barber, B., and Lyons, A. (2009). Pathway to Life Success: A Conceptual Model of Financial Well-being for Young Adults. Journal of Applied Development Psychology, vol. 30, pp. 708 - 723.

[57] Shockey, S.S. (2002). Low-wealth adults' financial literacy. Money management behavior and associated factors, including critical thinking. Unpublished master's thesis, University of Utah. 
[58] Stone, D., Wier, B., and Bryant. S. (2008). Reducing Materialism through Financial Literacy. CPA Journal, vol. 78, no. 2, pp. 12 - 14.

[59] Szulansky, G. (1996). Exploring internal stickiness: impediments to the transfer of best practice within the Firm. Strategic Management Journal, 17, Winter Special Issue, pp. 27- 43.

[60] Verona, G., Prandelli, E., and Sawhney, M. (2006). Innovation and Virtual nvironments: Towards Virtual Knowledge Brokers. Organization Studies, vol. 27, no. 6, pp. $765-788$.

[61] Vitt, L.A., Anderson, C., Kent, J., Lyter, D.M., Siegenthaler, J.K., and Ward, J. (2000). Personal Finance and the Rush to Competence: Financial Literacy Education in the U.S. Middleburg, VA: Institute for Socio-Financial Studies. Available at: http://www.isfs.org/rep_finliteracy.pdf.

[62] Worthington, A. (2004). The distribution of financial literacy in Australia. Queensland University of Technology, Working Paper no. 185.

[63] Zia, B. and Xu, L. (2012). Financial Literacy Around the World: An Overview of the Evidence with Practical Suggestions for the Way Forward. World Bank Policy Research, Working Paper, no. 6107. 


\section{Appendices}

Appendix 1: Factor Loadings for the First Construct: Financial Literacy

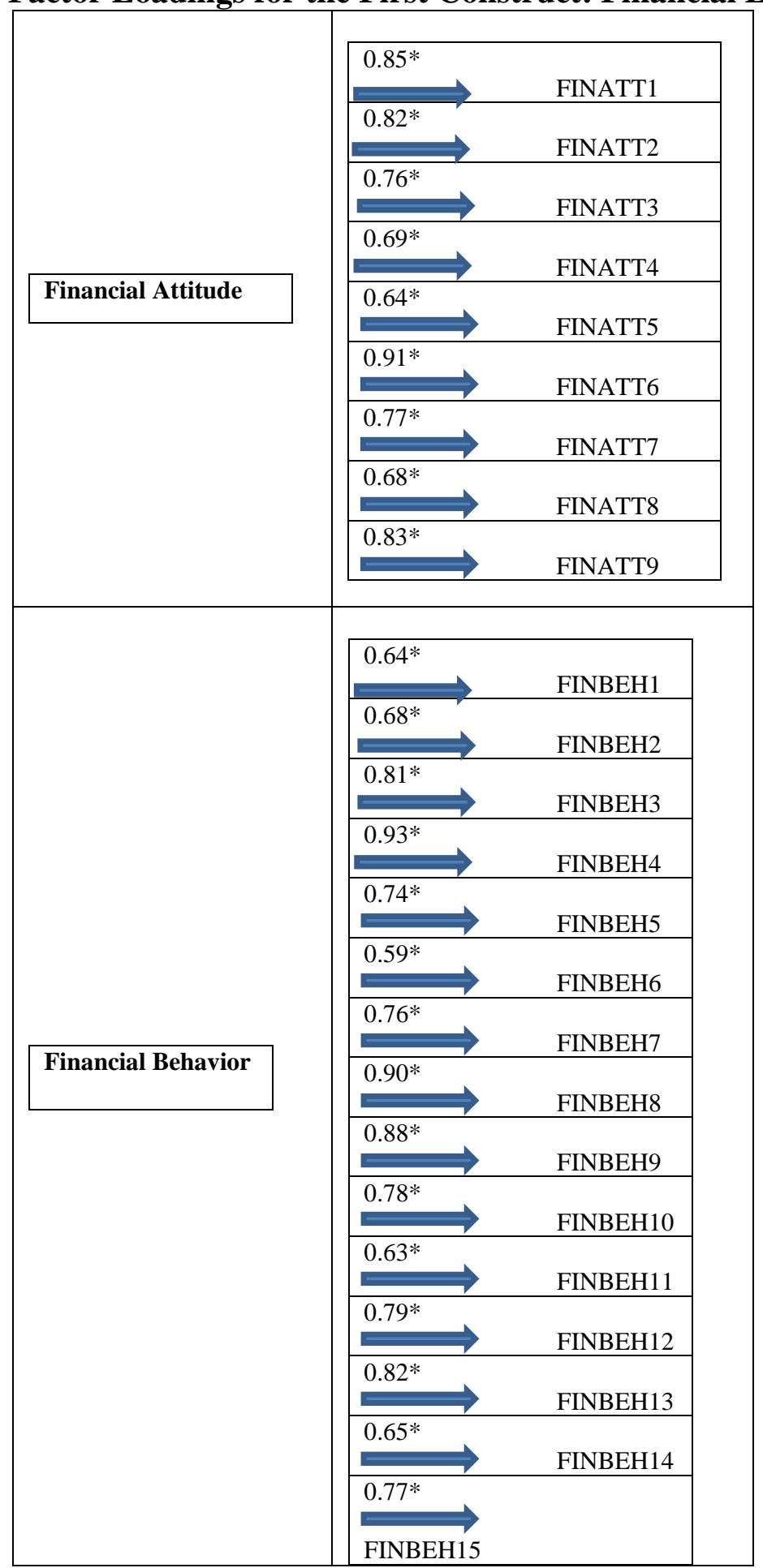




\begin{tabular}{|c|c|c|}
\hline & $0.86^{*}$ & BAFINK1 \\
\hline \multirow[t]{2}{*}{$\begin{array}{c}\text { Basic Financial } \\
\text { Knowledge }\end{array}$} & $0.75^{*}$ & BAFINK2 \\
\hline & $0.81^{*}$ & BAFINK3 \\
\hline & $0.79 *$ & ADFINK1 \\
\hline \multirow{3}{*}{$\begin{array}{c}\text { Advanced Financial } \\
\text { Knowledge }\end{array}$} & $0.83^{\circ}$ & ADFINK2 \\
\hline & $0.66^{*}$ & ADFINK3 \\
\hline & $0.92 *$ & ADFINK4 \\
\hline
\end{tabular}

Appendix 2: Factor Loadings for the Second Construct: Financial Knowledge Transfer

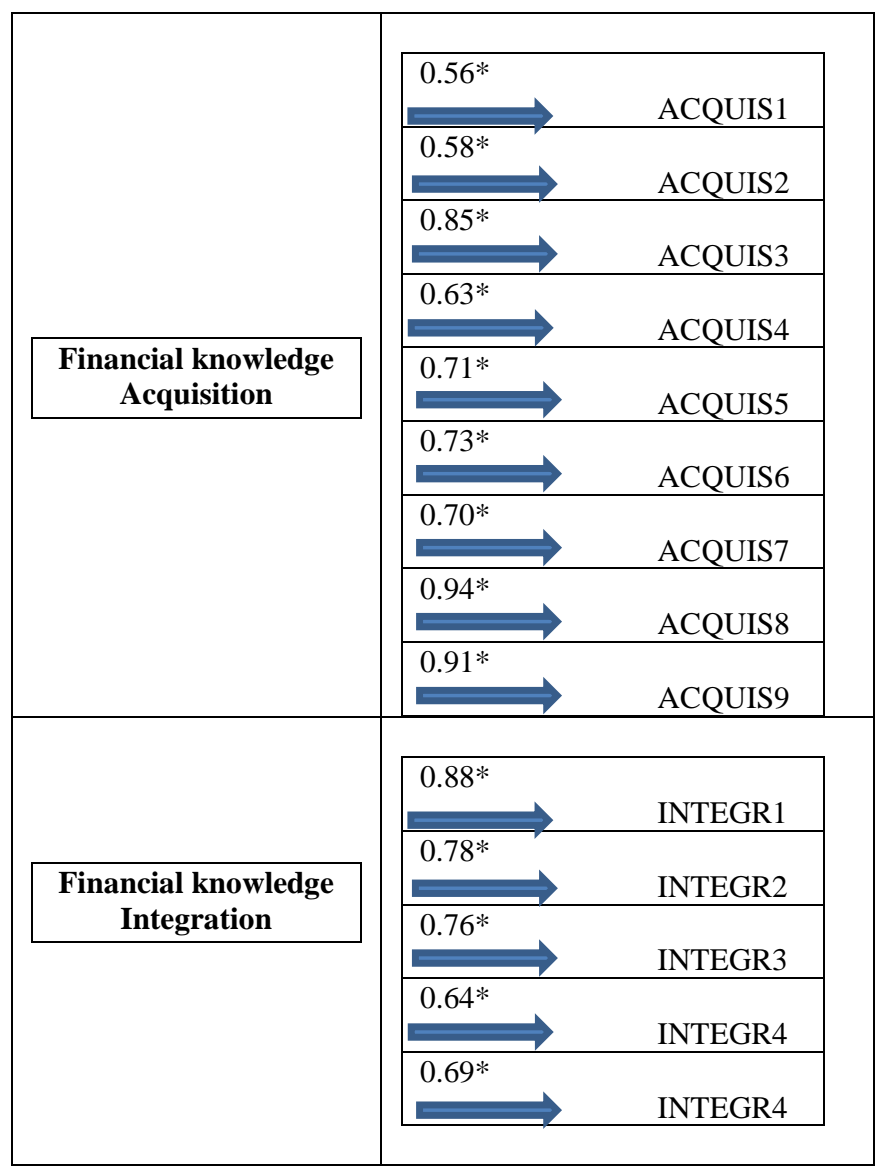




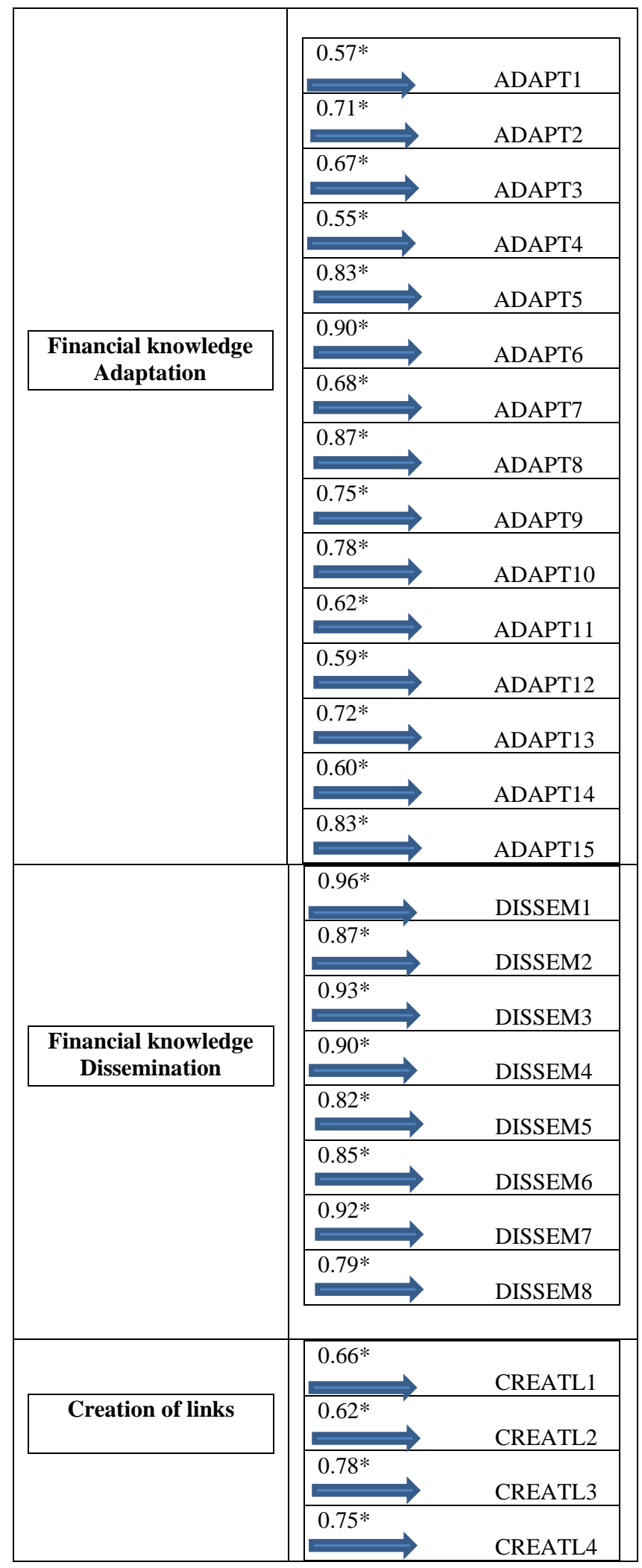

